Vol 11, Issue 12, 2018

\title{
EFFECT OF VITAMIN D SUPPLEMENTATION ON INSULIN SENSITIVITY AND ANDROGEN LEVEL IN VITAMIN D-DEFICIENT POLYCYSTIC OVARY SYNDROME PATIENTS
}

\author{
SABA M SWADI AL-THUWAYNEE ${ }^{1}$, AMAAL RAAD AHMED ${ }^{2 *}$ \\ ${ }^{1}$ Department of Obstetrics and Gynecology, College of Medicine, University of Al-Qadisiyah, Iraq. ${ }^{2}$ Department of Family Medicine, Al- \\ Dewaniyah Teaching Hospital, Al-Diwaniyah, Iraq. Email: ammal.raad.a@gmail.com
}

Received: 10 August 2018, Revised and Accepted: 06 September 2018

\section{ABSTRACT}

Objectives: There is limited evidence that giving Vitamin D supplementation had a beneficial effect on insulin resistance and dysfunction of the menstrual cycle in females with polycystic ovary syndrome (PCOS). Thus, the aim of the present study is to evaluate the effect of Vitamin D supplementation on insulin sensitivity and androgen level in Iraqi females with PCOS.

Methods: A randomized, blinded clinical trial design studied 60 Iraqi females with PCOS referring to the women's counseling, outpatients at maternity and pediatrics teaching hospital in AL-Qadisiyah city, Iraq, and private clinic. Non-probabilistic sampling involved women aged from 18 to 45 years established on inclusion criteria. The patients' basic data have been recorded. Then, we measured Vitamin D, testosterone level, and impaired glucose tolerance (IGT) test to all females. After the diagnosis of Vitamin D deficiency, Vitamin D was administering at 5000 units daily for 8 weeks. All data were remeasured after 2 months.

Result: A total of 60 patients with polycystic syndrome enrolled in the study, age range from 18 to 39 years, mean age $27.48 \pm 5.95$ years. The metabolic parameter have been checked at the beginning of the study, which include Vitamin D level 16.1 \pm 5.6 , impaired glucose test reading $8.8 \pm 0.7$ and testosterone level $4.5 \pm 0.64$.. After 2 months of supplementation, there were $83.7 \%$ of patients reach the normal level of Vitamin D and $16.3 \%$ still had a low level of Vitamin D ( $\mathrm{p} \leq 0.002)$ between two groups. In regard to IGT test after 2 months of supplementation, there were $51.6 \%$ of patients still who had impaired test while $48.4 \%$ reach the normal reading ( $\mathrm{p} \leq 0.001)$.

Conclusions: Women with PCOS have a statically significant low level of Vitamin D in mean, IGT test in the mean, and high level of testosterone, and there were inverse correlations between Vitamin D with IGT and testosterone.

Keywords: Polycystic ovary syndrome, Vitamin D, Impaired glucose tolerance.

(c) 2018 The Authors. Published by Innovare Academic Sciences Pvt Ltd. This is an open access article under the CC BY license (http://creativecommons. org/licenses/by/4. 0/) DOI: http://dx.doi.org/10.22159/ajpcr.2018.v11i12.29036

\section{INTRODUCTION}

Polycystic ovary syndrome (PCOS) is the most common ovarian disorder associated with the disturbances of reproductive, hyperinsulinemia, and androgen excess in women [1]. Definition and diagnosis of PCOS are based on criteria including clinical evidence of hyperandrogenism, ovarian dysfunction such as oligoovulation, and the exclusion of other causes of hyperandrogenism such as adrenal hyperplasia, hyperprolactinemia, and thyroid disorders [2]. PCOS is associated with insulin resistance, hypertension, central lipidemia, and central venous dysfunction, all of which are risk factors for metabolic syndrome, type 2 diabetes, and coronary artery disease [3].

Metabolic disturbances are common in PCOS women: $30-40 \%$ have glucose tolerance disorder, $60-80 \%$ are resistant to insulin, and $10 \%$ have type 2 diabetes in their 30s or 40s. Evidence suggests the pivotal role of insulin resistance in PCOS pathogenicity [4]. Decrease level of Vitamin D is common in women with PCOS [5]. Vitamin D deficiency in PCOS women was associated with a reduced likelihood of these women becoming pregnant and delivering babies, regardless of body mass index (BMI), race, age, markers of metabolic functioning, or fertility treatment" [6]. Vitamin $\mathrm{D}$ has been associated with reducing androgen levels in women with PCOS. A review of six clinical trials with 183 women with PCOS revealed that Vitamin D supplementation significantly reduced total testosterone levels [7].

\section{METHODS}

\section{Study design}

After having permission from the Ethics Committee of AL-Qadisiyah University of Medical Sciences, this study was conducted as a randomized, blinded clinical trial design from April 2018 to June 2018, and we studied 60 Iraqi females with polycystic ovary syndrome referring to the women's counseling, outpatients at maternity and pediatrics teaching hospital in AL-Qadisiyah city, Iraq. In our study, the aim of the project was explained to all females, and if they agreed, informed consent was obtained.

\section{Inclusion criteria}

The following criteria were included in the study:

1. Age of women ranges from 18 to 45 years.

2. Serum Vitamin D below $30 \mathrm{ng} / \mathrm{ml}$.

3. Women should not being pregnant or lactating.

4. Rotterdam criteria for PCOS diagnosis have been use [2] so patient should encounter at least two things of these criteria including: Oligoovulation or anovulation, hyperndrogenesis with a clinical or laboratory diagnosis. and, Polycystic ovary characterized by ultrasound that means atleast 12 follicles per ovary, or 9-2 $\mathrm{mm}$ in size, or ovarian enlargement more than $10 \mathrm{ml}$ (obtained from the formula $(0.5$ - length - width - thickness) in ultrasound [8].

5. All women which included in this study have testosterone level between 3.5 and $5 \mathrm{nmol} / \mathrm{L}$ (normal level of testosterone in females between 0.5 and $3.5 \mathrm{nmol} / \mathrm{L}$ )

6. Drugs which affect metabolic parameters such as metformin, Corticosteroid 3 months before the experiment, calcium and multivitamin 3 months before the experiment did not be used.

7. Screening for impaired glucose tolerance (IGT) test, and women with $2 \mathrm{~h}$ plasma glucose level of $140-199 \mathrm{mg} / \mathrm{dl}(7.8-11.0 \mathrm{mmol} / \mathrm{L})$ were involved in this study. 
Asian J Pharm Clin Res, Vol 11, Issue 12, 2018, 456-458

\section{Exclusion criteria}

Diseases which are chronic, for example, chronic kidney disease, liver cirrhosis, pancreatitis, nephrotic syndrome, tumors, and diabetes mellitus and patient who is being suffering from Cushing's syndrome, hyperprolactenemia, the congenital adrenal hyperplasia, and androgen secretion tumors were excluded from the study.

\section{Measurement Methods}

Calculation of BMI

By measuring body weight in kilograms using a digital scale. Quantitative test of total $25(\mathrm{OH}) \mathrm{D} 2 / \mathrm{D} 3$ level in human serum/plasma was measured by ICHROMA DEVICE using immunofluorescence method by Vitamin D kit. Testosterone level was measured using fluorescence immunoassay method (FIA). IGT is performed to all females included in this study. After diagnosis of IGT test depend on if blood glucose between 7.8 and $11.0 \mathrm{mmol} / \mathrm{L}$ this indicate impaired glucose test and then patient included in our study.

\section{Clinical assessment}

In includes the determination of hirsutism using modified Ferriman-Gallwey scoring system [9]. It should be noted that all trails were conducted at single private laboratories to increase reliability and minimize the variance between laboratories After the diagnosis of Vitamin D deficiency, Vitamin D was administering at 5000 units daily or 50,000 units weekly for 8 weeks according to patients' wish and availability of the drug for each woman in this study. All data were also remeasured 2 months after the start of the treatment.

\section{RESULTS}

Sixty patients with polycystic syndrome enrolled in this study age ranging from 18 to 39 years, mean age $27.48 \pm 5.95$ years, as shown in Table 1. In the beginning of the study, the level of Vitamin D was $16.11 \pm 5.6$ and, after 2 months, became $35.9 \pm 4.3$ which is a significant difference $(\mathrm{p}=0.002)$ as shown in Table 2 .

In regard to IGT test after 2 months of supplementation, there were $51.6 \%$ of patients still who had impaired test while $48.4 \%$ reach the normal reading $(\mathrm{p}=0.001)$ (Table 3$)$. On the other hand, $75 \%$ of patients reach the normal level of testosterone and $25 \%$ had abnormal level $(\mathrm{p}=0.001)$ (Table 4).

Table 5 shows inverse correlations between Vitamin D with IGT and testosterone, which mean an increase in Vitamin D level after supplementation leading to decrease in serum level of testosterone $(\mathrm{p}=0.02)$ and also decrease in the reading of impaired tolerance test $(\mathrm{p}=0.04)$.

\section{DISCUSSION}

Our result indicated women with PCOS have a significant low level of Vitamin D in mean 16.11 \pm 5.6 , IGT test in mean 8.8 \pm 0.8 , and high level of testosterone in mean $4.5 \pm 0.6[10,11]$. These indicate that low Vitamin D levels are associated with insulin resistance in women with PCOS [12]. Our data suggest a relationship of Vitamin D and BMI in PCOS women, which is in agreement with many studies $[8,13,14]$. Other studies suggest that low Vitamin D levels are related to impaired glucose clearance, insulin secretion, and insulin resistance $[15,16]$.

The IGT level at baseline was $8.8 \pm 0.9$, and after treatment, $48.4 \%$ became normal reading ( $6.4 \pm 0.8)$; t-test showed a significant difference between the level of IGT before and after treatment $(p<0.05)$.

On the other hand, the level of testosterone was $4.5 \pm 0.6$ before treatment, while $75 \%$ after treatment decreases to normal level $(2.2 \pm 0.4)(p<0.05)$. A significant fall in serum testosterone was observed in 2 months in comparison with the baseline in the same group. A similar result has also been described in a study by Pal et al. [9]. Several factors may be able to explain the conflicting results, including the different characteristics of the research subjects, the length of study, and the various Vitamin D forms used for supplementation [17-19].
Table 1: Age distribution

\begin{tabular}{ll}
\hline Age $($ mean \pm SD) & $27.48 \pm 5.95$ \\
Minimum & 18 \\
Maximum & 39 \\
\hline SD: Standard deviation
\end{tabular}

SD: Standard deviation

Table 2: Level of serum Vitamin D through the study

\begin{tabular}{llll}
\hline Time & No. & Vitamin D & p value \\
\hline At baseline & 60 & $16.11 \pm 5.6$ & 0.002 \\
After 2 months & 50 & $35.9 \pm 4.3$ & \\
\hline
\end{tabular}

Table 3: IGT after 2 months

\begin{tabular}{llll}
\hline IGT after 2 months & $\mathbf{N}(\%)$ & Mean \pm SD & p value \\
\hline Impaired & $31(51.6)$ & $8.2 \pm 0.4$ & 0.001 \\
Normal & $29(48.4)$ & $6.4 \pm 0.8$ & \\
Total & 60 & & \\
\hline
\end{tabular}

SD: Standard deviation, IGT: Impaired glucose tolerance

Table 4: Testosterone level after 2 months

\begin{tabular}{llll}
\hline Testosterone after 2 months & $\mathbf{N}(\%)$ & Mean \pm SD & p value \\
\hline Normal & $45(75)$ & $2.2 \pm 0.4$ & 0.001 \\
Abnormal & $15(25)$ & $4.02 \pm 0.8$ & \\
Total & 60 & & \\
\hline
\end{tabular}

IGT: Impaired glucose tolerance

Table 5: Correlation between Vitamin D and IGT and testosterone level

\begin{tabular}{lll}
\hline Parameter & r & p value \\
\hline IGT & -0.39 & 0.02 \\
Testosterone & -0.15 & 0.04 \\
\hline
\end{tabular}

IGT: Impaired glucose tolerance

\section{CONCLUSION}

Women with PCOS have statistically significant low level of Vitamin D in mean, IGT test in mean, and high level of testosterone in mean. After Vitamin D supplementation for 2 months, 42 of 54 PCOS women previously affected by menstrual disturbances reported improvement of menstrual frequency. Also there was marked reduction in the level of IGT after treatment with Vitamin D have been reported. Furthermore, there is an improvement in the symptom of hyperandrogenism.

\section{AUTHORS' CONTRIBUTIONS}

Saba M. Swadi Al-Thuwaynee: Contributing to the conception, study design, and data interpretation. Amaal Raad Ahmed: Contributing to sample collection, writing the manuscript, and statistical analysis.

\section{CONFLICTS OF INTEREST}

There are no conflicts of interest.

\section{REFERENCES}

1. Conway G, Dewailly D, Diamanti-Kandarakis E, Escobar-Morreale HF, Franks S, Gambineri A, et al. The polycystic ovary syndrome: A position statement from the European society of endocrinology. Eur J Endocrinol 2014;171:1-29.

2. Krul YH, Snackey C, Louwers Y. The role of Vitamin D in metabolic disturbances in PCOS. Eur J Endocrinol 2013;169:853-65.

3. Rahimi-Ardabili H, Gargari BP, Farzadi L. Vitamin D supplementation has no effect on insulin resistance assessment in women with polycystic 
ovary syndrome and Vitamin D deficiency. Nutr Res 2012;3:195-201.

4. Thomson RL, Spedding S, Brinkworth GD, Noakes M, Buckley JD. Seasonal effects on Vitamin D status influence outcomes of lifestyle intervention in overweight and obese women with polycystic ovary syndrome. Fertil Steril 2013;99:1779-85.

5. Faraji R, Sharami SH, Zahiri Z, Asgharni M, Kazemnejad E, Sadeghi S. Evaluation of relation between anthropometric indices and Vitamin D concentrations in women with polycystic ovarian syndrome. J Family Reprod Health 2014;8:123-9.

6. Bergiota A, Diamanti-Kandarakis E. The effect of old, new and emerging medicines on metabolic aberrations in PCOS. Ther Adv Endocrinol Metab 2012;1:27-47.

7. Banuls C, Rovira-Llopis S, Martinez de Maranon A, Veses S, Jover A, Gomez M, et al. Metabolic syndrome enhances endoplasmic reticulum, oxidative stress and leukocyte-endothelium interactions in PCOS. Metabolism 2017;71:153-62.

8. Li HW, Breteton RE, Anderson RA, Wallace AM, Ho CK. Vitamin D deficiency is common and associated with metabolic risk factors in pateints with polycystic ovary syndrome. Metabolism 2011;60:1475-81.

9. Gallea M, Granzotto M, Azzolini S, Faggian D, Mozzanega B, Vettor R, et al. Insulin and bodyweight but not hyperandrogenism seem involved in seasonal serum 25-OH-Vitamin D3 levels in subjects affected by PCOS. Gynecol Endocrinol 2014;30:739-45.

10. Hahn S, Haselhorst U, Tan S, Quadbeck B, Schmidt M, Roesler S, et al.Low serum 25-hydroxyvitamin D concentrations are associated with insulin resistance and obesity in women with polycystic ovary syndrome. Exp Clin Endocrinol Diabetes 2006;114:577-83.

11. Tzotzas T, Papadopoulou FG, Tziomalos K, Karras S, Gastaris K, Perros $\mathrm{P}$, et al. Rising serum 25-hydroxy-Vitamin D levels after weight loss in obese women correlate with improvement in insulin resistance.
J Clin Endocrinol Metab 2010;95:4251-7.

12. Mm AA, Alias A, Sajith M, Nimbargi V, Kumdale S. Prescription pattern in obese and non-obese infertile women with polycystic ovary syndrome in a tertiary care hospital. Asian J Pharm Clin Res 2018;11:53-6.

13. Garg G, Kachhawa G, Ramot R, Khadgawat R, Tandon N, Sreenivas V, et al. Effect of Vitamin D supplementation on insulin kinetics and cardiovascular risk factors in polycystic ovarian syndrome: A pilot study. Endocr Connect 2015;4:108-16.

14. Raja-Khan N, Shah J, Stetter CM, Lott ME, Kunselman AR, Dodson WC, et al. High dose Vitamin D supplementation and measures of insulin sensitivity in polycystic ovarian syndrome. Fertile Steril 2014:101:1740-6.

15. He C, Lin Z, Robb SW, Ezeamama AE. Serum Vitamin D levels and polycystic ovary syndrome: A systematic review and meta-analysis. Nutrients 2015;7:4555-77.

16. Kataria J, Gill GK, Kaur M. Interrelationship of thyroid hormones, obesity, and prolactin in infertile women. Asian J Pharm Clin Res 2018;11:136-7.

17. Ardabili HR, Gargari BP, Farzadi L. Vitamin D supplementation has no effect on insulin resistance assessment in women with polycystic ovary syndrome and vitamin D deficiency. Nutr Res 2012;32:195-201.

18. Fang F, Ni K, Cai Y, Shang J, Zhang X, Xiong C. Effect of Vitamin D supplementation on polycystic ovary syndrome: A systematic review and meta-analysis of randomized controlled trials. Complement Ther Clin Pract 2017;26:53-60.

19. Mahmoudi T, Gourabi H, Ashrafi M, Yazdi RS, Ezabadi Z. Calciotropic hormones, insulin resistance, and the polycysticovary syndrome. Fertil Steril 2010;93:1208-14. 